\title{
Polycystic ovarian syndrome: pathogenesis and management
}

\author{
Coumba Aicha Thiam ${ }^{1 *}$, Malyn M. L. K. Antoine ${ }^{2}$, Chrystal D. Antoine-Frank ${ }^{3}$
}

\begin{abstract}
${ }^{1}$ Department of Obstetrics and Gynaecology, ${ }^{2}$ Department of Endocrinology, Zhongnan Hospital of Wuhan University, Wuhan, Hubei, China

${ }^{3}$ Department of Anatomical Sciences, St. George's University, True Blue, Grand Anse, St. George, Grenada, West Indies
\end{abstract}

Received: 08 December 2020

Accepted: 13 January 2021

\author{
*Correspondence: \\ Dr. Coumba Aicha Thiam, \\ E-mail: aichathiam17@gmail.com
}

Copyright: (c) the author(s), publisher and licensee Medip Academy. This is an open-access article distributed under the terms of the Creative Commons Attribution Non-Commercial License, which permits unrestricted non-commercial use, distribution, and reproduction in any medium, provided the original work is properly cited.

\begin{abstract}
Polycystic ovarian syndrome (PCOS) is an endocrine disorder that commonly affects women of reproductive age. Its prevalence varies quite significantly and its clinical presentation includes: reproductive, metabolic and psychological issues. PCOS develops due to a variety of factors some of which are not yet fully understood. Due to the complexity in the development and presentation of this condition, the management of PCOS in most instances is complicated and involves the combination of pharmacological, non-pharmacological and surgical interventions. This review discusses the pathogenesis and management of PCOS as means of providing information that would enhance understanding and control of this disease.
\end{abstract}

Keywords: Hyperandrogenemia, Insulin resistance, Polycystic ovarian syndrome, Type-2 diabetes mellitus

\section{INTRODUCTION}

PCOS is considered one of the most common endocrine disorders affecting women of reproductive age $\mathrm{e}^{1,2}$ Although the aetiology of this condition is unknown, the prevalence of PCOS has been proven to vary quite widely ranging from as low as $2.2 \%$ to as high as $26 \% .^{3}$ The clinical presentations of this disease are quite variable and include: reproductive problems such as infertility, metabolic manifestations such as type II diabetes mellitus (T2DM) and psychological issues such as depression. ${ }^{4}$

Research into the pathophysiology of this condition has led to significant discoveries regarding PCOS, some of which have brought to light the importance of insulin resistance and obesity as part of the presentation of the syndrome. ${ }^{5,6}$ This knowledge is important as it directs clinicians to not only focus on managing the common manifestations of PCOS, such as infertility and hyperandrogenemia, but to also take into consideration the metabolic abnormalities that may present as part of this disease. As it relates to the pathogenesis of PCOS, different theories have been proposed for its development. PCOS is considered multifactorial and evidence suggests that it potentially develops due to various factors which may be genetic or environmental in nature. ${ }^{7,8}$

Despite the wealth of knowledge already acquired on this condition, much research is still required into its pathogenesis and aetiology. In addition, with the general effects that PCOS has on the body (reproductive, metabolic and psychological) physicians may often struggle to successfully control the clinical manifestations and associated features of the syndrome.

Therefore, this review serves to further investigate the pathogenesis and management of PCOS as means of providing clinicians with the necessary information needed to not only understand this disease but to also effectively manage and control its presentation. 


\section{TYPES OF PCOS}

Takai et al described PCOS based on androgenic function. Their study identified three types of PCOS: ${ }^{9}$

Type I: Characterized by an absence of features of hirsutism and no increase in androgen levels (androstenedione and or testosterone)

Type 2: Characterized by an absence of features of hirsutism with elevated levels of androgens.

Type 3: Characterized by both features of hirsutism and elevated blood levels of androgens.

\section{DIAGNOSTIC CRITERIA FOR PCOS}

A series of criteria has been developed for use in the diagnosis of PCOS. In1990, at a conference on PCOS sponsored by The National Institutes of Health/National Institute of Child Health and Human Development (NIH/ NICHHD), the following criteria, with features presented in order of importance, were developed for the diagnosis of PCOS: a) high levels of androgens manifested clinically or biochemically, b) prolonged anovulation and c) the elimination of other similar conditions such as thyroid diseases or hyperprolactinemia. ${ }^{10,11}$

In 2003, another conference, which was sponsored by two bodies, the American Society for Reproductive Medicine and the European Society for Human reproduction and Embryology, was held in Rotterdam, Netherlands. During this conference, the following three features were identified as part of the diagnostic criteria for PCOS: a) oligoovulation or anovulation, b) increased levels of androgens manifested clinically or biochemically and c) polycystic ovaries (PCOs) detected upon ultrasound examination. After the successful exclusion of other similar disorders, the Rotterdam criteria require the presence of at least two out these three features for the accurate diagnosis of PCOS. ${ }^{12}$ The Rotterdam criteria added two diagnostic features to the NIH criteria: a) the presence of PCOs with an increased androgen production in the absence of ovulatory problems and b) the presence of PCOs with ovulatory problems in the absence of an increased production of androgens. ${ }^{13}$

In 2006 further reviews led to the amendment of the diagnostic criteria for PCOS by a board of experts from The Androgen Excess Society (AES). The AES recommended that the presence of excess androgens be given great attention as a critical feature for diagnosing PCOS. According to the AES criteria, in order for a diagnosis of PCOS to be given, the following features are required: a) hyperandrogenism detected clinically or biochemically, combined with b) irregular ovulation and/or the presence of PCOs. ${ }^{14}$
Table 1: Summary of diagnostic criteria for polycystic ovarian syndrome.

\begin{tabular}{|c|c|c|}
\hline Criteria & $\begin{array}{l}\text { Year of } \\
\text { development }\end{array}$ & Features \\
\hline NIH/NICHHD & 1990 & $\begin{array}{l}\text { Excess androgen } \\
\text { production and chronic } \\
\text { anovulation }\end{array}$ \\
\hline Rotterdam & 2003 & $\begin{array}{l}\text { Excess androgen } \\
\text { production, chronic } \\
\text { anovulation and } \\
\text { Polycystic ovaries on } \\
\text { ultrasound examination } \\
\text { NB: Requires the } \\
\text { presence of at least two } \\
\text { of these features for } \\
\text { diagnosis }\end{array}$ \\
\hline AES & 2006 & $\begin{array}{l}\text { Excess androgen } \\
\text { production, irregular } \\
\text { ovulation and/or } \\
\text { polycystic ovaries on } \\
\text { ultrasound examination }\end{array}$ \\
\hline
\end{tabular}

\section{Pathogenesis}

PCOS is considered a multifactorial condition which may develop due to different genetic or environment causes. The following identifies hormonal, neuroendocrine, genetic and developmental factors that may contribute to the development of this syndrome.

\section{Hormonal factors}

The role of Anti-Mullerian hormone (AMH) in the development of PCOS has been investigated extensively. This hormone is normally produced in the male foetus where it supports the degeneration of the mullerian duct. In females, it is produced by ovarian granulosa cells. ${ }^{15}$

In the ovaries, AMH renders the developing follicles less sensitive to follicle stimulating hormone (FSH). It also interferes with the normal functioning of the ovaries and the enzyme aromatase; therefore, inhibiting the initiation of the primordial follicle. In a study carried out by Durlinger et al to investigate the effects of AMH on the recruitment of primordial follicles, ovaries from 2 day old mice were harvested and cultured. After culturing these ovaries for 2 to 4 days, it was observed that there was a decrease in the number of growing follicles in ovaries that were exposed to AMH as compared to the control. ${ }^{16}$ Therefore, this demonstrated that AMH may have the ability to directly affect developing primordial follicles.

Another study was carried out by Durlinger et al to examine the effects that AMH has on the ovaries. In this study the entire ovarian population of three categories of mice were examined: 1$) \mathrm{AMH} \mathrm{(+/+)} \mathrm{(wild-type)} \mathrm{2)} \mathrm{AMH}$ 
(-/-) (AMH null) and 3) AMH (+/-) (heterozygous AMH null mutation) mice. Ovaries used in this study were harvested from females that were 25-days, 4months, and 13-months old. Comparison of the three identified groups demonstrated that the total population of primordial ovarian follicles decreased with age across the three groups. In addition, it was observed that the rate of decrease was more rapid among the AMH $(-/-)$ group as compared to the AMH $(+/+)$ group of mice. ${ }^{17}$ The latter observation demonstrates that in the absence of AMH more primordial follicles were recruited for growth and development and thus reveal the negative effects that the presence of AMH may have on the recruitment of primordial follicles for development.

In addition to $\mathrm{AMH}$, insulin is another hormone that is thought to contribute significantly to the development of PCOS. 44-70\% of individuals suffering from PCOS experience some degree of insulin resistance and abnormal blood glucose levels. ${ }^{18}$ The insulin resistance that presents with PCOS is a major contributor to its pathogenesis. Insulin resistance leads to high levels of blood insulin and glucose in addition to exaggerated oxidative stress; factors which cumulatively contribute to the development of the major features observed in PCOS.

To this point, it is not yet fully understood exactly how insulin impairment contributes to the manifestation of the syndrome; however it is believed that insulin dysfunction contributes to abnormal insulin signalling or impairment in the normal functioning of insulin receptors. This in turn results in hyperinsulinemia and reduced hepatic clearance of insulin from the blood. ${ }^{19}$ It is postulated that hyperinsulinemia also plays an important role in the pathogenesis of PCOS by stimulating ovarian cells to increase their production of testosterone or by decreasing the levels of sex hormone binding proteins (SHBP) in the blood.

In addition, insulin has the potential to influence gonadotropin levels through its effects on the hypothalamus and pituitary gland. Furthermore, hyperinsulinemia influences the adrenal gland to augment adrenocorticotropic hormone (ACTH) driven androgen production. $^{20}$

Insulin works along with gonadotropins in stimulating ovarian granulosa cells to produce steroids. It is also observed that in the presence of elevated insulin levels, granulosa cells become more sensitive to luteinizing hormone (LH); a phenomenon which is thought to be responsible for the anovulation observed in PCOS. ${ }^{21}$ It is demonstrated that follicles harvested from normal ovaries only respond to the gonadotropin LH when the follicles obtain an optimal size of about $10 \mathrm{~mm}$. However, on the other hand, follicles harvested from the ovaries of PCOS individuals respond to $\mathrm{LH}$ at much smaller sizes (as small as $4.5 \mathrm{~mm}$ ). This difference in response to $\mathrm{LH}$ may be due to the presence of elevated blood insulin levels observed in PCOS patients. ${ }^{22}$

\section{Neuroendocrine factors}

Studies into the relationship between AMH and the development of PCOS show that PCOS patients exhibit a significantly higher level of AMH as compared to control groups. ${ }^{23,24}$ An in-vivo study was carried out to demonstrate the effects of AMH on $\mathrm{LH}$ secretion through recruitment of the hypothalamic neurons that release gonadotropin releasing hormone $(\mathrm{GnRh})$. It was demonstrated that AMH increases LH levels by binding to $\mathrm{AMH}$ receptors found on $\mathrm{GnRh}$ neurons in the hypothalamus. ${ }^{25}$ In patients with PCOS, AMH inhibits FSH release while it induces an increase in LH secretion. LH levels are therefore significantly increased with a typical increase in the LH: FSH ratio, a finding which is a classical feature of PCOS. ${ }^{26}$

\section{Genetic factors}

Research evidence suggests a genetic arm to the development of PCOS. ${ }^{27}$ Twin studies demonstrate that this condition is highly hereditable with a stronger correlation of the condition being observed amongst monozygotic twins as compared to dizygotic twins. ${ }^{28}$ Furthermore, studies have also attempted to assign autosomal dominant and $\mathrm{x}$-linked modes of inheritance for this condition; however, due to limitations in study designs, selection methods and the categorization of the features of the syndrome, results obtained in this regard are majorly inconclusive. ${ }^{29-31}$

A procedure called the transmission disequilibrium test (TDT) has been applied with success in identifying potential genetic defects that may be associated with certain features of PCOS. TDT is used to determine and link the transmission of susceptible genes from parents to offsprings. ${ }^{32}$ With the use of this test, a defect linked to the reproductive phenotype (hyperandrogenemia) observed in PCOS patients was identified on Chromosome 19p 13.2 (dinucleotide repeat D19S884). A case-control study which investigated 85 Caucasian females with PCOS showed a relationship between the D19S884 genetic defect and PCOS. ${ }^{33}$ However, two larger case control studies, which investigated this association in Caucasian females of European decent, both failed to further demonstrate an association between this identified genetic defect and PCOS. ${ }^{34,35}$

The fibrillin-3 gene has also been identified for the role that it may play in the pathogenesis of PCOS. ${ }^{36}$ Observation of both polycystic and non-polycystic ovaries shows that PCOs demonstrate a marked reduction in their expression of fibrillin-3 in stromal cells immediately surrounding follicles maturing from primordial to primary follicles; a phase of follicular development which is usually affected in PCOS. ${ }^{19}$

\section{Developmental factors}

Fetal programming is another factor that has been 
postulated as a major contributor to the pathogenesis of PCOS. ${ }^{37}$ Prenatal exposure to excessive androgens and restricted intrauterine growth has both been identified for the role that they may play in this phenomenon.

\section{Prenatal exposure to excess androgens}

Studies on rhesus monkeys demonstrated that female offsprings, exposed to excess androgens prenatally, exhibit reproductive and metabolic features of PCOS during adolescent periods of their development. ${ }^{38,39}$ In humans, it is theorized that females exposed to elevated levels of androgens at any point starting from the beginning of fetal ovarian development to the commencement of puberty are predisposed to developing reproductive and metabolic features of PCOS.40,41 However, further research is required to fully understand the role that prenatal exposure to excess androgens may play in the development of PCOS in humans as previous evidence shows contrary results. ${ }^{42}$

\section{Restricted intrauterine growth}

It has been proposed that restricted intrauterine growth resulting in low birth weight predisposes girls to developing features of PCOS during puberty. ${ }^{43,44}$
However, further research is required to fully understand this effect in humans as research has yielded inconclusive or opposing results in this regard. ${ }^{45,46}$

\section{MANAGEMENT}

The management of PCOS can be broken down into three major categories: non-pharmacological, pharmacological and surgical approaches. The treatment of PCOS is designed to provide long term protection for patients and to prevent the development of associated complications such as diabetes, depression or anxiety. It is also important in preventing major issues of infertility and malignancies ${ }^{47}$. The treatment regimen selected for PCOS is highly dependent on the signs and symptoms that are present and it can be adapted to match the individual's needs and circumstances. While developing a treatment plan for managing this condition, it is important to bear in mind that insulin resistance is viewed as the most common pathogenic factor that contributes to the major metabolic disturbances observed in this syndrome. Insulin resistance is observed in about $75 \%$ of individuals suffering from PCOS and 70-95\% of PCOS patients are obese while $30-75 \%$ are lean. ${ }^{48}$ Tables 2,3 and 4 highlights the treatment options and recommendations for treating the manifestations of PCOS.

Table 2: Highlighting the targets and the benefits of different treatment methods used in PCOS.

\begin{tabular}{|c|c|c|}
\hline & Target & Benefits \\
\hline Non-pharmacological & $\begin{array}{l}\text { Hyperinsulinemia } \\
\text { Hyperandrogenemia } \\
\text { Hyperglycemia } \\
\text { Infertility } \\
\text { Obesity }\end{array}$ & $\begin{array}{l}\text { Weight loss } \\
\text { Improves metabolic (hyperglycemia) } \\
\text { and reproductive issues } \\
\text { Improves ovulation } \\
\text { Reduces anxiety and depression } \\
\text { Improves self-esteem }\end{array}$ \\
\hline Pharmacological & $\begin{array}{l}\text { Hirsutism related to hyperandrogenemia } \\
\text { Anovulationlmenstrual dysfunction and infertility }\end{array}$ & $\begin{array}{l}\text { Improves ovulation and menstruation } \\
\text { Improves fertility } \\
\text { Improves metabolic abnormalities } \\
\text { Improves hirsutism and acne }\end{array}$ \\
\hline Surgical & Blood androgens and testosterone levels & $\begin{array}{l}\text { Improves acne and hirsutism } \\
\text { Improves menstruation } \\
\text { Improves ovulation } \\
\text { Improves fertility }\end{array}$ \\
\hline
\end{tabular}

\section{NON-PHARMACOLOGICAL}

Lifestyle modifications such as diet and exercises are natural methods that play pivotal roles in the management of PCOS. It is observed that lifestyle interventions have the potential to improve infertility issues and metabolic disturbances. It is also implied that lifestyle modifications can possibly reduce future risks for developing diabetes and cardiovascular diseases. ${ }^{49}$ All these benefits are derived from a general improvement in the state of insulin resistance that is usually observed with the application of lifestyle changes. Lifestyle modifications are considered as part of the first-line therapy for PCOS.
Since the prevalence of obesity is quite alarming in women suffering from PCOS, weight reduction is given high priority during treatment. Weight loss in PCOS patients has been associated with observed improvements in metabolic and reproduction issues. ${ }^{49-51}$ Evidence reveals that weight reduction by as little as 5\%, potentially improves ovulation cycles and restores normal menstruration. ${ }^{52}$

The use of exercise regimens such as Hiit and steady training are shown to improve insulin sensitivity. ${ }^{50}$ Physical activities may also have some benefits on psychological manifestations as it helps to improve states 
of depression and anxiety. Weight loss resulting from exercises also positively impacts perceptions of body image which in turn helps to improve self-esteem. ${ }^{53,54}$

Blood glucose levels stimulate pancreatic beta-cells to produce insulin and are normally affected by carbohydrate consumption. Since impaired blood glucose regulation and insulin resistance are commonly seen in PCOS patients, diet control is also an important factor to consider in the management of the disease. PCOS patients should consume diets low in carbohydrates. Examples of low carbohydrate diets (LCD) include: 1) ketogenic diet (daily carbohydrate intake is less than $30 \mathrm{~g}$, or a total of $5 \%$ of daily energy intake, and 2) mediterranean diet (involves the consumption of a variety of fruits and vegetables including nuts and seeds; also requires minimal intake of dairy products and red meat). ${ }^{55}$ LCD diets have been shown to improve reproductive and metabolic problems in PCOS patients. In addition, they improve the symptoms that are related to hyperandrogenemia. They also aid in reducing blood glucose and insulin levels in addition to increasing plasma levels of FSH and SHBG. Increased circulation of FSH and SHBG reduce testosterone levels and also help to reverse the hypothalamic-hypophyseal dysfunction that is normally responsible for the fertility issues seen in PCOS. ${ }^{56}$
Furthermore, the use of supplements has also been recommended for treating PCOS. Since different nutrients potentially regulate insulin signalling pathways and the synthesis of androgens, their deficiency may be linked to the development of some common complications of PCOS. ${ }^{57}$ Therefore, the use of supplements in the form of vitamins or minerals may be used to complement the treatment of PCOS. ${ }^{52}$ Vitamins such as vitamins A,B,D,E or inositol has antioxidant properties which have several potential benefits including: 1) help in oocyte maturation, 2) decrease cardiovascular risk factors, 3) improve menstruation, 4) improve fertility, 5) improve endometrial lining thickness, and 6) reduce androgen levels. Minerals such as calcium, chromium and zinc, may also contribute to improvements in ovulatory cycles, menstruation, and metabolic profiles in patients diagnosed with PCOS. ${ }^{57}$

Another method that is observed for its effectiveness in the management of PCOS is fasting or intermittent fasting. During periods of fasting, blood glucose levels are low which in turn lowers blood insulin levels. Fasting combined with dietary and other lifestyle modifications have proven quite effective in lowering blood insulin levels, promoting weight loss, improving skin conditions and increasing ovulation. ${ }^{58}$

Table 3: Summarizing the treatment methods available for treating polycystic ovarian syndrome.

\begin{tabular}{|c|c|c|}
\hline Non-pharmacological & Pharmacological & Surgical \\
\hline Lifestyle modification & Hirsutism and hyperandrogenemia & \multirow{19}{*}{ LOD } \\
\hline Diet & 1) Estro-progestins pills & \\
\hline Exercise & Oral contraceptives combining oestrogen and progestin & \\
\hline Dietary supplements & 2) Anti-androgens & \\
\hline Vitamins A, B, D, E or inositol & Androgen receptor blockers & \\
\hline \multirow{14}{*}{ Minerals: calcium, chromium, zinc } & Spironolactone & \\
\hline & Flutamide & \\
\hline & Alpha reductase inhibitors & \\
\hline & Finasteride & \\
\hline & 3) Insulin-sensitizing agents & \\
\hline & Biguanides-metformin & \\
\hline & TZDs & \\
\hline & Ovarian\menstrual dysfunction and infertility & \\
\hline & MPA & \\
\hline & Metformin & \\
\hline & GLP-1 receptor agonists & \\
\hline & $\mathrm{CC}$ & \\
\hline & Gonadotropins & \\
\hline & Letrozole & \\
\hline
\end{tabular}

GLP-1- Glucagon-like peptide-1, CC- Clomiphene Citrate, TZDs- Thiazolidinedones, LOD- Laparoscopic Drilling, MPAMedroxyprogesterone acetate

\section{PHARMACOLOGICAL APPROACHES}

When weight loss seems difficult or in instances where PCOS patients are of normal body weight or are underweight, the use of various pharmacological agents may prove helpful in treating the disease. Pharmacological agents mainly target the symptoms and complications of PCOS such as hirsutism related to 
hyperandrogenemia and anovulation\menstrual dysfunction and infertility.

\section{Hirsutism and hyperandrogenemia}

In cases where hirsutism is mild or localized, simple cosmetic measures may be sufficient for management and control. However, in instances where hirsutism is moderate or severe, pharmacological intervention becomes imperative. Treatment options usually preferentially target hyperandrogenemia, since excess androgen production is the main influencing factor for the development of hirsutism. In the presence of hyperandrogenemia, estro-progestins or anti-androgens are used as mono-therapy or in combination with ethinylestradiol. If required, insulin sensitizers such as metformin are also included as part of the treatment regimen. ${ }^{59}$

Oral contraceptive pills (OCPs) that combine oestrogen with progestin are the primary option employed when managing hirsutism and acne in PCOS. ${ }^{60}$ Progestin potentially suppresses LH levels, which results in decreased androgen production from the ovaries. Oestrogen, on the other hand, increases SHBG, thus reducing the levels of free androgens in the blood. ${ }^{61}$ These pharmacological options are excellent choices for controlling hirsutism in PCOS as they are inexpensive, safe and are very effective in controlling acne and hyperandrogenemia. ${ }^{60}$ Anti-androgens can also be successfully used for managing hirsutism and hyperandrogenemia when oestrogen-progestin combinations seem ineffective. Drugs that are currently used to counteract the effects of androgens in the blood include androgen receptor blockers such as spironolactone and flutamide, and $5 \alpha$-reductase inhibitors such as finasteride. ${ }^{59}$ These classes of pharmacological agents work by reducing the effects or the levels of androgen in the blood and they have the added benefit of regulating blood lipid levels. ${ }^{60}$ Flutamide, though effective, potentially impairs liver function and should be used with caution or administered at lower doses when used for the management of PCOS in teenagers and adults. In general, anti-androgens can cause abnormal development in male foetuses; therefore, with their use, contraception is recommended. ${ }^{60}$ The combination of anti-androgens with oestrogen-progestin pills is proven more effective in successfully treating hirsutism as compared to the use of oestrogen-progestin pills alone. ${ }^{61}$

Insulin-sensitizing agents may also be used as part of the treatment regimen; however, their use is still questionable as evidence shows that their effects on hyperandrogenemia and hirsutism are only moderate. ${ }^{61}$ Medications that may be considered as insulin-sensitizers include biguanides (metformin) and thiazolidinediones (TZDs). Metformin can potentially control hyperinsulinemia and therefore, decrease insulinstimulated androgen production by the ovaries. The use of TZDs in the treatment of hyperandrogenemia and hirsutism in PCOS may be limited as its use potentially supports weight gain. ${ }^{51}$

\section{Management of ovarian\menstrual dysfunction and infertility}

Ovarian dysfunction and chronic anovulation are common in PCOS patients and are due to hyperinsulinemia, hyperandrogenemia and obesity that are usually present as part of the syndrome. Anovulation is primarily responsible for observed infertility and reproductive issues; therefore, if ovulation is successfully restored fertility issues would also be resolved. With this in mind, the main aim when treating fertility problems in PCOS women is to achieve mono-follicular development. $^{62,63}$

In PCOS patients there is hormonal dysregulation in the hypothalamic-pituitary-gonadal (HPG) axis, causing increased blood levels of androgens and oestrogen in addition to increased LH and decreased FSH levels. These effects lead to abnormal menstruation and amenorrhea (observed in $75 \%$ to $85 \%$ of PCOS patients). ${ }^{59}$ The use of medication in the management of ovarian dysfunction in PCOS should only be employed after the patient is fully educated on the risks and benefits that may accompany this method of treatment. Traditionally, OCPs are used in the long-term management of PCOS. OCPs prevent overgrowth of the endometrium and therefore, protect patients against cancers. OCPs are often used as they help to regulate menstrual cycles and improve co-morbidities by decreasing plasma levels of LH thus reducing hyperandrogenemia. ${ }^{59}$ It is important to note that the use of OCPs is not recommended in patients who smoke, has a history of breast cancer or in patients with a significant family history for heart diseases. ${ }^{64}$

The following medications may prove helpful in the management of ovarian/menstrual dysfunction and infertility in PCOS.

\section{Medroxyprogesterone acetate}

Medroxyprogesterone acetate (MPA) is a progestin or female hormone that potentially regulates ovulation and menstruation. This pharmacological agent can be applied to the management of various conditions which may include: amenorrhea or dysfunctional uterine bleeding. It can also be used to prevent endometrial overgrowth and therefore, reduces the risk for developing uterine cancers. MPA also has the added benefits of promoting insulin sensitivity and improving blood lipid profiles in PCOS patients. ${ }^{60}$ It can also be used in PCOS women to avoid pregnancies.

\section{Metformin}

Women who are diagnosed with PCOS face an increased risk for developing diabetes mellitus (DM) and usually 
have elevated insulin levels. Insulin resistance is quite common in PCOS patients and it contributes significantly to the ovulatory abnormalities that are often present. Metformin can be used in PCOS women to reduce the risk of diabetes or to treat diabetes if it has already developed. Metformin is an insulin sensitizing agent and it therefore, promotes insulin sensitivity, thus decreasing blood insulin levels. This in turn suppresses insulin stimulated androgen production from the ovaries, potentially supporting menstruation. ${ }^{51}$ It is often used in women who have difficulties achieving weight loss. It is also used as an add-on therapy in women who experience menstrual irregularities or women who are unable to use estro-progestinics. This medication may also be prescribed particularly in instances where there are impaired glucose tolerance (IGT). ${ }^{55}$

The use of metformin can also contribute to improvement in fertility in PCOS women. Metformin regulates the levels of reproductive hormones in the blood and therefore helps in restoring ovulation. In addition, metformin may also induce weight loss in PCOS women in whom infertility drugs are used to achieve ovulation. ${ }^{65}$ Metformin helps to improve fertility rates in PCOS women who experience fertility issues. ${ }^{59}$ This is achieved through an induced reduction in blood insulin levels, thus causing normal release of $\mathrm{GnRH}$ and gonadotropins. ${ }^{66}$ Evidence suggests that prescribing metformin prior to the introduction of infertility drugs or the attempt of in-vitro fertilization, increases the rates of ovulation and successful pregnancies. Despite the promising effects of the use of metformin on fertility, its clinical effects may become evident following weeks of treatment as the onset of this drug is gradual and slow. ${ }^{65}$

The use of metformin is associated with a myriad of side effects (nausea, diarrhoea, abdominal pain, bloating); therefore, its use is often substituted by other insulin sensitizers. Evidence suggests that treatment with TZDs is effective in PCOS patients and TZDs are prescribed as second-line management options in PCOS patients who are overweight or exhibit insulin resistance. ${ }^{67}$

\section{Glucagon-like peptide-1 (GLP-1) receptor agonists}

Glucagon-like peptide-1 (GLP-1) receptor agonists is a novel class of drug proven effective in the management of T2DM. In addition to lowering blood glucose levels, GLP-1 receptor agonists also reduces body weight and promotes insulin sensitivity. Additionally, in PCOS patients who are obese or overweight, this drug class improves menstruation and suppresses blood levels of androgen. Combination therapies of GLP-1 receptor agonists and metformin are potentially more effective than their mono-therapy in the management of metabolic and reproductive abnormalities of PCOS; however, further studies are pending to determine the full effects of combination therapy with these agents. ${ }^{51}$

\section{Clomiphene citrate}

Clomiphene Citrate (CC) provides a simple and cost effective way of promoting ovulation in PCOS women. It is described as a weak oestrogen-like hormone. This drug exhibits its effects on endocrine glands (hypothalamus, pituitary and ovaries), thus increasing the plasma levels of LH and FSH. This is achieved through the potential of $\mathrm{CC}$ to prevent the binding of estradiol to receptors in these major glands therefore, eliminating the negative feedback loop for endogenous oestrogens and estradiol. ${ }^{59}$ By inhibiting the negative feedback loop between the ovaries, pituitary gland and the hypothalamus, CC directly induces ovulation and thus directly target infertility issues that are observed in PCOS. Evidence reveals that the use of $\mathrm{CC}$ is associated with ovulation rates of about $60 \%-85 \%$ and pregnancy rates of about $(30 \%-50 \%)$ following six ovulatory cycles. ${ }^{68}$

$\mathrm{CC}$ is considered the first-line treatment option for the complication of infertility in PCOS. Increased FSH levels increases the chance for ovum maturation and ovulation. $\mathrm{CC}$ exhibits the potential to induce mono-follicular development and carries a low possibility for causing multiple pregnancies (2 to $13 \%) .{ }^{69}$

The use of this drug is associated with side effects such as ovarian hyper-stimulation syndrome (OHSS), bloating, ovarian enlargement, hot flashes and multiple pregnancies. ${ }^{70}$ If following six months of treatment women are non-responsive to $\mathrm{CC}$, then $\mathrm{CC}$ resistance is present. In instances like these, a second pharmacological agent is added or second-line therapy is required. Metformin is the most recommended add on therapy when resistance occurs and the combination of metformin with $\mathrm{CC}$ in the presence of $\mathrm{CC}$ resistance increases the rates of ovulation and successful pregnancies. ${ }^{65,70}$

\section{Gonadotropins}

In PCOS patients who are not responsive to metformin or clomiphene, Human menopausal gonadotropin (HMG) daily injections serve excellent alternatives. Gonadotropins (LH and FSH) are hormones naturally produced by the pituitary gland. These hormones promote follicle maturation and ovulation. The use of gonadotropins in the treatment of ovulatory dysfunctions in PCOS may yield greater effects than the use of clomiphene. Despite this fact, $\mathrm{CC}$ is favoured as first-line therapy in the management of infertility issues in PCOS as it is easier to administer and is more cost effective as compared to the use of gonadotropins. Since FSH promotes follicular growth, its use, as part of therapy, may result in multiple pregnancies or OHSS due to an over response of the ovaries to the hormone. ${ }^{69}$ These risks factors are controlled through the co-administration of gonadotropins with letrozole as the use of letrozole reduces the length of stimulation and amount of gonadotropins required for a desired effect. ${ }^{71}$ 


\section{Letrozole}

Letrozole prevents the conversion of androgens to oestrogen. As a result, when utilized in the management of PCOS, letrozole directly addresses fertility complications through its potential to inhibit the negative feedback loop between the ovaries, hypothalamus and pituitary gland. The mechanism of action of this drug promotes a rise in the plasma levels of FSH which in turn induces follicle development, maturation and ovulation. Letrozole is more effective than $\mathrm{CC}$ in addressing fertility abnormalities of PCOS as it is associated with improved gestational outcomes and greater events of live births. Even though the World Health Organization (WHO) supports the use of letrozole as first-line treatment for ovulation induction and some guidelines propose letrozole as an alternative to clomiphene, more research on safety and efficacy is required due to concerns risen regarding congenital malfunctions associated with the use of letrozole. ${ }^{71}$

\section{SURGICAL APPROACH}

The use of surgical interventions aids to decrease the plasma levels of $\mathrm{LH}$ and testosterone. This in turn promotes the successful restoration of normal, regular menstruation in addition to controlling symptoms of acne and hirsutism. Surgical methods directly destroy parts of the ovaries (follicles and surrounding stroma), therefore, reducing the amount of androgens that are available for conversion through aromatization. This induces an increased secretion of FSH, thus supporting follicular development, maturation and ovulation. ${ }^{72}$

Laparoscopic drilling (LOD) is the surgical method that is now preferred over laparotomy and ovarian wedge surgeries. This procedure can be utilized in patients who are resistant to $\mathrm{CC}$. It carries many advantages which include: 1) helps to decrease potential risks for developing OHSS, 2) promotes mono-ovulation, 3) supports higher pregnancy rates, 4) reduces length of time to pregnancy and 5) decreases the need for ovulation promoting drugs. ${ }^{72}$ Studies demonstrate that the performance of LOD on one ovary or both ovaries shows no major differences in outcomes. However, unilateral interventions are deemed more appropriate in reducing the occurrence of adverse effects. As with all surgical procedures, LOD may be associated with intra and postoperative complications. Bleeding and infections may occur. In addition, during LOD, if the ovaries are extensively damaged, the woman may enter menopause prematurely. It is also important to note that this procedure is not permanent and with time menstrual irregularities may re-occur. ${ }^{73}$

Table 4: Highlighting recommendation for the treatment of infertility in polycystic ovarian syndrome. ${ }^{74}$

\begin{tabular}{|c|c|}
\hline Treatment option & Recommendations \\
\hline Lifestyle modifications & $\begin{array}{l}\text { In cases where the patient is overweight or obese, lifestyle changes are required as the } \\
\text { first-line treatment for PCOS. It provides tremendous benefits in improving mental states, } \\
\text { reproductive issues and metabolic abnormalities. }\end{array}$ \\
\hline \multicolumn{2}{|c|}{ Pharmacological approaches } \\
\hline Letrozole & Recommended as part of the first-line treatment for inducing ovulation in PCOS. \\
\hline $\mathrm{CC}$ & $\begin{array}{l}\text { Recommended as part of the first-line treatment for PCOS; however, it is slightly less } \\
\text { effective than letrozole. }\end{array}$ \\
\hline Metformin & $\begin{array}{l}\text { Can be used as a mono-therapy as part of the first-line treatment for PCOS; however, it is } \\
\text { slightly less effective as compared to clomiphene citrate and letrozole. }\end{array}$ \\
\hline $\begin{array}{l}\text { Combination therapy of } \\
\text { clomiphene citrate and } \\
\text { metformin }\end{array}$ & $\begin{array}{l}\text { This combination therapy can be considered for its use as a first-line therapy in the } \\
\text { treatment of PCOS. Clomiphene citrate combined with metformin provides more benefits } \\
\text { for obese patients as compared to the single use of metformin. In addition, in all women } \\
\text { particularly those that are resistant to clomiphene citrate, the use of this combination is } \\
\text { more effective as compared to the single use of clomiphene citrate. Despite these benefits } \\
\text { that are potentially derived from this treatment combination, it is not recommended over } \\
\text { letrozole as the first-line treatment in PCOS. }\end{array}$ \\
\hline Gonadotropins & $\begin{array}{l}\text { Can be considered as part of the second-line treatment regimen for PCOS in instances } \\
\text { where first-line treatments are proven ineffective. The use of gonadotropins is more } \\
\text { effective in women who are resistant to clomiphene citrate as compared to the use of the } \\
\text { combination therapy of clomiphene citrate and metformin. In addition, in women that are } \\
\text { resistant to clomiphene citrate, gonadotropins can be combined with metformin. } \\
\text { Gonadotropins can be considered for use as first-line therapy and is seen as more } \\
\text { effective when combined with ultrasound monitoring. In this instance, it should only be } \\
\text { considered after the patient is educated on its cost and possible risk of multiple } \\
\text { pregnancies. }\end{array}$ \\
\hline LOD & $\begin{array}{l}\text { Recommended as part of the second-line treatment regimen when patient is resistance to } \\
\text { clomiphene citrate. }\end{array}$ \\
\hline
\end{tabular}

CC- Clomiphene citrate, LOD- Laparoscopic ovarian drilling, PCOS- Polycystic Ovarian Syndrome Laparoscopic ovarian drilling 


\section{CONCLUSION}

In conclusion, PCOS is a multifactorial disorder which may develop secondary to hormonal, neuroendocrine, genetic and developmental factors. Its management involves the combination of non-pharmacological, pharmacological and surgical interventions. PCOS remains a complex condition and more research is required to further understand the role that genetics and excess androgen exposure during development may play in its development. In addition, more exploration is needed into the side effect profile of the drugs that are currently used for the treatment of this condition and probably into the production of drugs that are capable of targeting the multiple complications that accompanies PCOS.

\section{Funding: No funding sources \\ Conflict of interest: None declared \\ Ethical approval: Not required}

\section{REFERENCES}

1. Balen AH, Morley LC, Misso M, Franks S, Legro $\mathrm{RS}$, Wijeyaratne $\mathrm{CN}$, et al. The management of anovulatory infertility in women with polycystic ovary syndrome: an analysis of the evidence to support the development of global WHO guidance. Hum Reprod Update. 2016;22(6):687-708.

2. Teede HJ, Misso ML, Costello MF, Dokras A, Laven J, Moran L, et al. Recommendations from the international evidence-based guideline for the assessment and management of polycystic ovary syndrome. Hum Reprod. 2018;33(9):1602-18.

3. March WA, Moore VM, Willson KJ, Phillips DI, Norman RJ, Davies MJ. The prevalence of polycystic ovary syndrome in a community sample assessed under contrasting diagnostic criteria. Hum Reprod. 2010;25(2):544-51.

4. Trikudanathan S. Polycystic ovarian syndrome. Med Clin North Am. 2015;99:221-35.

5. Vgontzas AN, Legro RS, Bixler EO, Grayev A, Kales A, Chrousos GP. Polycystic ovary syndrome is associated with obstructive sleep apnea and daytime sleepiness: role of insulin resistance. J Clin Endocrinol Metab. 2001;86(2):517-20.

6. Venkatesan AM, Dunaif A, Corbould A. Insulin resistance in polycystic ovary syndrome: progress and paradoxes. Recent Prog Horm Res. 2001;56:295308.

7. Spritzer PM. Polycystic ovary syndrome: reviewing diagnosis and management of metabolic disturbances. Arq Bras Endocrinol Metab. 2014;58:182-7.

8. Nelson VL, Legro RS, Strauss III JF, McAllister JM. Augmented androgen production is a stable steroidogenic phenotype of propagated theca cells from polycystic ovaries. Molecular endocrinology. 1999 Jun 1;13(6):946-57.
9. Takai I, Taii S, Takakura K, Mori T. Three types of polycystic ovarian syndrome in relation to androgenic function. Fertil Steril. 1991;56(5):856-62.

10. Azziz R, Carmina E, Chen Z, Dunaif A, Laven JS, Legro RS, et al. Polycystic ovary syndrome. Nat Rev Dis Prime. 2016;2(1):1-8.

11. Asunción M, Calvo RM, San Millán JL, Sancho J, Avila S, Escobar-Morreale HF. A prospective study of the prevalence of the polycystic ovary syndrome in unselected Caucasian women from Spain. J Clin Endocrinol Metab. 2000;85(7):2434-8.

12. Azziz, R. Diagnosis of polycystic ovarian syndrome: the Rotterdam criteria are premature. J Clin Endocrinol Metab. 2006;91:781-5.

13. Hsu MI, Liou TH, Chou SY, Chang CY, Hsu CS. Diagnostic criteria for polycystic ovary syndrome in Taiwanese Chinese women: comparison between Rotterdam 2003 and NIH 1990. Fertil Steril. 2007;88:727-9.

14. Mohammad MB, Seghinsara AM. Polycystic ovary syndrome (PCOS), diagnostic criteria, and AMH. Asian Pac J Cancer Prev. 2017;18:17-21.

15. Durlinger A, Visser J, Themmen A. Regulation of ovarian function: the role of anti-Mullerian hormone. Reproduction. 2002.

16. Durlinger AL, Gruijters MJ, Kramer P, Karels B, Ingraham HA, Nachtigal MW, et al. Anti-Mullerian hormone inhibits initiation of primordial follicle growth in the mouse ovary. Endocrinology. 2002;143(3):1076-84.

17. Durlinger AL, Kramer P, Karels B, de Jong FH, Uilenbroek JT, Grootegoed JA, et al. Control of primordial follicle recruitment by anti-Mullerian hormone in the mouse ovary. Endocrinology. 1999;140(12):5789-96.

18. Macut D, Bjekić-Macut J, Rahelić D, Doknić M. Insulin and the polycystic ovary syndrome. Diabetes Res Clin Pract. 2017;130:163-70.

19. Diamanti-Kandarakis E, Dunaif A. Insulin resistance and the polycystic ovary syndrome revisited: an update on mechanisms and implications. Endocr Rev. 2012;33(6):981-1030.

20. Maqbool M, Dar MA, Gani I, Geer MI. Insulin resistance and polycystic ovary syndrome: a review. J Drug Deliv Ther. 2019;9:433-6.

21. Nestler JE, Jakubowicz DJ, Falcon de Vargas A, Brik C, Quintero N, Medina F. Insulin stimulates testosterone biosynthesis by human thecal cells from women with polycystic ovary syndrome by activating its own receptor and using inositolglycan mediators as the signal transduction system. J Clin Endocrinol Metab. 1998;83(6):2001-5.

22. Weiss JM, Polack S, Diedrich K, Ortmann, O. Effects of insulin on luteinizing hormone and prolactin secretion and calcium signaling in female rat pituitary cells. Arch Gynecol Obstet. 2003;269:45-50.

23. Laven JS, Mulders AG, Visser JA, Themmen AP, De Jong FH, Fauser BC. Anti-Mullerian hormone serum concentrations in normoovulatory and anovulatory 
women of reproductive age. J Clin Endocrinol Metabolism. 2004;89(1):318-23.

24. Cook CL, Siow Y, Brenner AG, Fallat ME. Relationship between serum müllerian-inhibiting substance and other reproductive hormones in untreated women with polycystic ovary syndrome and normal women. Fertil Steril. 2002;77:141-6.

25. Cimino I, Casoni F, Liu X, Messina A, Parkash J, Jamin SP, et al. Novel role for anti-Müllerian hormone in the regulation of $\mathrm{GnRH}$ neuron excitability and hormone secretion. Nat Commun. 2016;7(1):1-2.

26. Wang F, Niu W, Kong H, Guo YH, Sun Y. The role of AMH and its receptor SNP in the pathogenesis of PCOS. Mol Cell Endocrinol. 2017;439:363-8.

27. Legro RS, Driscoll D, Strauss JF, Fox J, Dunaif A. Evidence for a genetic basis for hyperandrogenemia in polycystic ovary syndrome. Proc Nat Acad Sci. 1998;95:14956-60.

28. Vink JM, Sadrzadeh S, Lambalk CB, Boomsma D. I. Heritability of polycystic ovary syndrome in a dutch twin-family study. J Clin Endocrinol Metab. 2006;91:2100-4.

29. Kashar-Miller M, Azziz R. Heritability and the risk of developing androgen excess. J Steroid Biochem Mol Biol. 1999;69:261-8.

30. Franks S, Gharani N, Waterworth D, Batty S, White $\mathrm{D}$, Williamson $\mathrm{R}$, et al. The genetic basis of polycystic ovary syndrome. Hum Reprod. 1997;12(12):2641-8.

31. Ehrman DA, Barnes RB, Rosenfield RL. Polycystic ovary syndrome as a form of functional ovarian hyperandrogenism due to dysregulation of androgen secretion. Endocr Rev. 1995;16:322-53.

32. Clayton D. A generalization of the transmission/disequilibrium test for uncertainhaplotype transmission. Am J Hum Genet. 1999;65:1170-7.

33. Tucci S, Futterweit W, Concepcion ES, Greenberg DA, Villanueva R, Davies TF, et al. Evidence for association of polycystic ovary syndrome in caucasian women with a marker at the insulin receptor gene locus. J Clin Endocrinol Metab. 2001;86(1):446-9.

34. Villuendas G, Tosi F, Sancho J, Moghetti P, San Millán JL. Association between the D19S884 marker at the insulin receptor gene locus and polycystic ovary syndrome. Fertil Steril. 2003;79(1):219-20.

35. Prodoehl MJ, Hatzirodos N, Irving-Rodgers HF, Zhao ZZ, Painter JN, Hickey TE, et al. Genetic and gene expression analyses of the polycystic ovary syndrome candidate gene fibrillin-3 and other fibrillin family members in human ovaries. Mol Hum Reprod. 2009;15(12):829-41.

36. Jordan CD, Bohling SD, Charbonneau NL, Sakai LY. Fibrillins in adult human ovary and polycystic ovary syndrome: is fibrillin-3 affected in PCOS? J Histochem Cytochem. 2010;58:903-15.
37. Dumesic DA, Abbott DH, Padmanabhan V. Polycystic ovary syndrome and its developmental origins. Rev Endocr Metab Disord. 2007;8:127-41.

38. Dumesic DA, Abbott DH, Eisner JR, Goy RW. Prenatal exposure of female rhesus monkeys to testosterone propionate increases serum luteinizing hormone levels in adulthood. Fertil Steril. 1997;67:155-63.

39. Eisner JR, Dumesic DA, Kemnitz JW, Colman R, Abbott DH. Increased adiposity in female rhesus monkeys exposed to androgen excess during early gestation. Obes Res. 2003;11:279-86.

40. Franks S, Mccarthy MI, Hardy K. Development of polycystic ovary syndrome: involvement of genetic and environmental factors. Int $\mathrm{J}$ Androl. 2006;29:278-85.

41. Cole B, Hensinger K, Maciel GAR, Chang RJ, Erickson GF. Human fetal ovary development involves the spatiotemporal expression of P450c17 protein. J Clin Endocrinol Metab. 2006;91:3654-61.

42. Hickey M, Sloboda DM, Atkinson HC, Doherty DA, Franks S, Norman RJ, et al. The relationship between maternal and umbilical cord androgen levels and polycystic ovary syndrome in adolescence: a prospective cohort study. J Clin Endocrinol Metab. 2009;94(10):3714-20.

43. Cresswell JL, Barker DJ, Osmond C, Egger P, Phillips DI, Fraser RB. Fetal growth, length of gestation, and polycystic ovaries in adult life. Lancet. 1997;350(9085):1131-5.

44. Ibáñez L, de Zegher F, Potau N. Premature pubarche, ovarian hyperandrogenism, hyperinsulinism and the polycystic ovary syndrome: from a complex constellation to a simple sequence of prenatal onset. J Endocrinol Invest. 1998;21:558-66 .

45. Laitinen J, Taponen S, Martikainen H, Pouta A, Millwood I, Hartikainen AL, et al. Body size from birth to adulthood as a predictor of self-reported polycystic ovary syndrome symptoms. Int $\mathrm{J}$ Obes. 2003;27(6):710-5.

46. Sadrzadeh S, Painter RC, Lambalk CB. Developmental origins of polycystic ovary syndrome (PCOS), a case control study comparing birth weight in women with PCOS and control group. Gynecol Endocrinol. 2016;32:856-9.

47. Tabassum R, Imtiaz F, Sharafat S, Shukar-ud-din S, Nusrat U. Prevalence and clinical profile of insulin resistance in young women of poly cystic ovary syndrome: a study from Pakistan. Pak J Med Sci. 2013;29:593-6.

48. McCall B. Long-term metformin in PCOS benefits women of all weights. Madescape Medical News. 2018. Available from: https://www.medscape.com/viewarticle/891653. Accessed on 23 September 2020.

49. Marshall JC, Dunaif A. All women with PCOS should be treated for insulin resistance. Fertil Steril. 2012;97:18-22.

50. Almenning I, Rieber-Mohn A, Lundgren KM, Løvvik TS, Garnæs KK, Moholdt T. Effects of high 
intensity interval training and strength training on metabolic, cardiovascular and hormonal outcomes in women with polycystic ovary syndrome: a pilot study. PLoS One. 2015;10(9):e0138793.

51. Sanchez-Garrido MA, Tena-Sempere M. Metabolic dysfunction in polycystic ovary syndrome: Pathogenic role of androgen excess and potential therapeutic strategies. Mol Metab. 2020;35:100937.

52. Hamilton KP, Zelig R, Parker AR, Haggag A. Insulin resistance and serum magnesium concentrations among women with polycystic ovary syndrome. Curr Dev Nutr. 2019;3.

53. Conte F, Banting L, Teede HJ, Stepto NK. Mental health and physical activity in women with polycystic ovary syndrome: a brief review. Sports Med Auckl Nz. 2015;45:497-504.

54. Hutchison SK, Stepto NK, Harrison CL, Moran LJ, Strauss BJ, Teede HJ. Effects of exercise on insulin resistance and body composition in overweight and obese women with and without polycystic ovary syndrome. J Clin Endocrinol Metab. 2011;96(1):E48-56.

55. Paoli A, Mancin L, Giacona MC, Bianco A, Caprio M. Effects of a ketogenic diet in overweight women with polycystic ovary syndrome. J Translat Med. 2020;18(1):1-1.

56. Zhang X, Zheng Y, Guo Y, Lai Z. The effect of low carbohydrate diet on polycystic ovary syndrome: a meta-analysis of randomized controlled trials. Int $\mathbf{J}$ Endocrinol. 2019;2019:4386401.

57. Günalan E, Yaba A, Yilmaz B. The effect of nutrient supplementation in the management of polycystic ovary syndrome-associated metabolic dysfunctions: A critical review. J Turk Ger Gynecol Assoc. 2018;19:220-32.

58. Chiofalo B, Laganà AS, Palmara V, Granese R, Corrado G, Mancini E, et al. Fasting as possible complementary approach for polycystic ovary syndrome: Hope or hype? Med Hypothes. 2017;105:1-3.

59. Pasquali R. Contemporary approaches to the management of polycystic ovary syndrome. Ther Adv Endocrinol Metab. 2018;9:123-34.

60. Porchia LM, Hernandez-Garcia SC, Gonzalez-Mejia ME, López-Bayghen E. Diets with lower carbohydrate concentrations improve insulin sensitivity in women with polycystic ovary syndrome: A meta-analysis. Eur J Obstet Gynecol Reprod Biol. 2020;248:110-7.

61. Pasquali R, Gambineri A. Therapy in endocrine disease: treatment of hirsutism in the polycystic ovary syndrome. Eur J Endocrinol. 2014;170:R7590.

62. Baptiste CG, Battista MC, Trottier A, Baillargeon JP. Insulin and hyperandrogenism in women with polycystic ovary syndrome. J Steroid Biochem Mol Biol. 2010;122:42-52.

63. Gadalla MA, Norman RJ, Tay CT, Hiam DS, Melder A, Pundir J, et al. Medical and surgical treatment of reproductive outcomes in polycystic ovary syndrome: an overview of systematic reviews. Int J Fertil Steril. 2020;13(4):257.

64. Orbetzova MM. Clinical Impact of Insulin Resistance in Women with Polycystic Ovary Syndrome. In: Polycystic Ovarian Syndrome. IntechOpen. 2020.

65. Nestler JE. Metformin in the treatment of infertility in PCOS: an alternative perspective. Fertil Steril. 2008;90:14-6.

66. Goodman NF, Cobin RH, Futterweit W, Glueck JS, Legro RS, Carmina E. American Association of Clinical Endocrinologists, American College of Endocrinology, and androgen excess and PCOS society disease state clinical review: guide to the best practices in the evaluation and treatment of polycystic ovary syndrome-part 1. Endocr Pract. 2015;21(11):1291-300.

67. Stout DL, Fugate SE. Thiazolidinediones for treatment of polycystic ovary syndrome. Pharmacotherapy. 2005;25:244-52.

68. Costello M, Garad R, Hart R, Homer H, Johnson L, Jordan $\mathrm{C}$, et al. A review of first line infertility treatments and supporting evidence in women with polycystic ovary syndrome. Med Sci. 2019;7(9):95.

69. Melo AS, Ferriani RA, Navarro PA. Treatment of infertility in women with polycystic ovary syndrome: approach to clinical practice. Clinics. 2015;70:765-9.

70. Takasaki A, Tamura I, Okada-Hayashi M, Orita T, Tanabe M, Maruyama S, et al. Usefulness of intermittent clomiphene citrate treatment for women with polycystic ovarian syndrome that is resistant to standard clomiphene citrate treatment. Reprod Med Biol. 2018;17(4):454-8.

71. Xi W, Liu S, Mao H, Yang Y, Xue X, Lu X. Use of letrozole and clomiphene citrate combined with gonadotropins in clomiphene-resistant infertile women with polycystic ovary syndrome: a prospective study. Drug Design Develop Therap. 2015;9:6001.

72. Sinha P, Chitra T, Papa D, Nandeesha $H$. Laparoscopic ovarian drilling reduces testosterone and luteinizing hormone/follicle-stimulating hormone ratio and improves clinical outcome in women with polycystic ovary syndrome. J Hum Reprod Sci. 2019;12:224-8.

73. Hashim HA, Foda O, El Rakhawy M. Unilateral or bilateral laparoscopic ovarian drilling in polycystic ovary syndrome: a meta-analysis of randomized trials. Arch Gynecol Obstet. 2018;297(4):859-70.

74. Costello MF, Misso ML, Balen A, Boyle J, Devoto L, Garad RM, et al. A brief update on the evidence supporting the treatment of infertility in polycystic ovary syndrome. ANZ J Obstet Gynaecol. 2019;59(6):867-73.

Cite this article as: Thiam CA, Antoine MMLK, Antoine-Frank CD. Polycystic ovarian syndrome: pathogenesis and management. Int $\mathrm{J}$ Reprod Contracept Obstet Gynecol 2021;10:803-13. 